\title{
क्षण
}

\section{Autorregulação da Aprendizagem na Educação a Distância - Análise das Produções Científicas Realizadas em Brasil e Portugal no período de 2010 a 2015}

\section{Janaína Copello Quintes Monnerat ${ }^{* 1}$, Maria Teresa Ribeiro Pessoa², Joaquim Armando Gomes Alves Ferreira ${ }^{3}$}

\footnotetext{
1 Doutoranda em Psicologia, Faculdade de Psicologia e Ciências da Educação/Universidade de Coimbra. Rua do Colégio Novo, 3000-115 Coimbra - CO - Portugal. janacquintes@gmail.com

2 Professora Associada, Faculdade de Psicologia e Ciências da Educação/Universidade de Coimbra. Rua do Colégio Novo, 3000-115 Coimbra - CO - Portugal. tpessoa@fpce.uc.pt

3 Professor Catedrático, Faculdade de Psicologia e Ciências da Educação/Universidade de Coimbra. Rua do Colégio Novo, 3000-115 Coimbra - CO - Portugal. jferreira@fpce.uc.pt
}

\section{Resumo}

A sociedade atual, do conhecimento e da informação, requer do ensino superior novas dinâmicas mediadas pelas tecnologias, constituindo-se, nesse contexto, a Educação a Distância como modalidade de ensino privilegiada. Tornam-se relevantes a análise e a compreensão das formas de aquisição de conhecimento nessa modalidade por parte dos alunos, sendo o estudo da variável autorregulação da aprendizagem priorizada dada a sua importância para o sucesso acadêmico dos mesmos. O presente trabalho, após pesquisa guiada pelos atuais e credíveis repositórios português e brasileiro, RCAAP e CAPES, analisou artigos, dissertações de mestrado e teses de doutorado no âmbito da autorregulação da aprendizagem na Educação a Distância publicados no Brasil e em Portugal no período de 2010 a 2015. Os resultados encontrados apontam para quatro abordagens principais: o portfólio, como instrumento com imenso potencial da aprendizagem autorregulada; as estratégias de aprendizagem como extremamente importantes nos processos de autorregulação; estudos centrados no tutor e na forma como estes podem promover a autorregulação nos alunos; e, por último, as TIC, ou seja, as aplicações hipermédia como apoio à aprendizagem autorregulada. São necessários estudos mais aprofundados sobre este tema, incluindo a ampliação das plataformas de busca para um resultado mais abrangente.

Palavras-chave: Autorregulação, E-learning, Educação a Distância. 


\title{
Self Regulation of Learning in the E-Learning Area - Analysis \\ of the Scientific Works Performed in Brazil and Portugal in \\ the Period of 2010 to 2015
}

\begin{abstract}
Higher education includes an integration of various technological tools and distance education is constituted as a privileged mode of education. It is relevant to the analysis and understanding of the ways of acquiring knowledge by the students and the study of self-regulation variable prioritized learning given its importance for academic success thereof. This study analyzed articles, dissertations and theses PhD under the Self-Regulation of Learning in Distance Education published in Brazil and Portugal in the period 2010 to 2015 in RCAAP's and CAPES's databases. The results point to four main approaches: the portfolio as a tool with great potential of selfregulated learning; learning strategies as extremely important in the self-regulation processes; studies centered tutor and how these may promote self-regulation in students; and, finally, ICT, so hypermedia applications like self-regulating support for learning. Further studies are needed on this topic including the expansion of search platforms to a broader result.
\end{abstract}

Keywords: Self regulation, E-learning, Distance education. 


\section{Introdução}

O trabalho realizado pela Comissão Internacional sobre Educação para o século XXI, que orientou as ações da Unesco, trouxe reflexões importantes sobre a Educação e a aprendizagem com base em uma visão holística, indicando que a educação deve organizar-se à volta de quatro aprendizagens fundamentais que são importantes para o desenvolvimento de todo indivíduo, definindo os pilares do conhecimento: aprender a conhecer (adquirir instrumentos de compreensão), aprender a fazer (para poder agir no contexto), aprender a viver em cooperação social (cooperação com os outros em toda atividade humana), aprender a ser (estar), sendo este o principal conceito que compreende todos os anteriores (Delors et al., 1998).

Apesar de a discussão sobre este tema ter sido iniciada em 1998, ao longo dos anos seguintes essas orientações encontram-se corroboradas e necessárias para pensar a Educação numa visão integral do ser humano, considerando as constantes mudanças numa sociedade marcada pela rápida evolução tecnológica:

A contemporaneidade e seus aparatos tecnológicos trouxeram um novo caminhar para a humanidade, na busca de conhecimentos globalizados, oportunizando compreender 0 que pensam as diferentes culturas e as diversas visões de cientistas no mundo todo, quase ao mesmo tempo que os conhecimentos são descobertos e divulgados. Novas exigências surgiram, provocando o que sempre se buscou, mas que nunca se consolidou no meio educacional, a mudança de uma metodologia, não mais bancária, mas proativa, possibilitando a aprendizagem em todo tempo e lugar (Garbelini \& Gonçalves, 2015, p. 90).

Numa era digital, estamos cada vez mais imersos em tecnologia, não sendo vislumbrados, em nenhum momento, sinais de estagnação ou abrandamento dessa evolução tecnológica; pelo contrário, cada vez mais novas pesquisas estão sendo realizadas e novas descobertas geram novos avanços tecnológicos. A tecnologia está favorecendo grandes mudanças na economia, na forma como nos comunicamos e nos relacionamos, e cada vez mais na maneira como aprendemos (Bates, 2015).

Nos últimos anos, a internet tem evoluído a partir da Web 1.0, (os conteúdos não podiam ser modificados pelos usuários, somente lidos) para a Web 2.0 em que há interação entre usuários, individualmente ou de forma colaborativa, para desenvolver conteúdo, criar e compartilhar informações (existem alguns elementos de wikis, blogs, 
redes sociais, os diversos ambientes de partilha de recursos etc.). É um novo modelo de inteligência coletiva, em que os esforços se podem somar à construção conjunta do conhecimento. Hoje, inclusive, fala-se do nascimento de uma terceira geração da Web, a Web 3.0, conexão entre a Web semântica, a inteligência artificial e a web 3D (Web Tridimensional), que tem o apoio dos usuários para criar conteúdos usando grande variedade de aplicações (Carrasco, López, Manzano \& Peris, 2012).

Tais inovações aumentam as vias de acesso à informação, mas não garantem um bom aproveitamento dela, o que implica o desenvolvimento de habilidades específicas, como a busca de informações em canais fiáveis, seleção da informação relevante, síntese e avaliação. Nesse sentido, aquele que não está preparado para enfrentar esses desafios pode encontrar dificuldades em lidar com essas informações.

Torna-se necessário no Ensino Superior e a distância refletir sobre a competência dos estudantes para serem ativos durante a aprendizagem, exercendo controle sobre seus processos cognitivos, metacognitivos e motivacionais, de modo a adquirir, organizar e transformar as informações adquiridas ao longo do tempo, principalmente em contextos em que a utilização das TIC torna-se extremamente necessárias no processo ensino-aprendizagem e é, em alguns casos, o único meio em que ocorre a comunicação entre alunos e professores, como é o caso da Educação a Distância (EaD), uma vez que, como ressalta Litto (1999), na Educação a Distância o aluno está distante do professor, durante todo ou a maior parte do tempo da realização do curso, utilizando meios tecnológicos para acessar a informação. Essa informação é transformada em conhecimento adquirido por meio dos processos da autorregulação da aprendizagem. No entanto, há pouca evidência de pesquisa que tenha sido realizada sobre o tema específico da autorregulação da aprendizagem em ambientes de aprendizagem aprimorados pela tecnologia (Carneiro, Lefrere, Steffens \& Underwood, 2011).

Este artigo tem por objetivo compreender a importância da autorregulação da aprendizagem na EaD, identificar, localizar, avaliar de forma crítica e sintetizar estudos que versaram sobre esse tema no período de 2010 a 2015, sendo publicados nos repositórios da Capes, no Brasil, e no RCAAP em Portugal. Nesse sentido, inicia de forma resumida acerca do constructo da autorregulação da aprendizagem, seguido da metodologia utilizada para a obtenção dos estudos, discussão dos resultados, e finaliza com algumas considerações. 


\section{O constructo da autorregulação da aprendizagem}

A compreensão dos processos psicológicos, internos e transacionais que impulsionam o indivíduo a buscar o alcance de suas metas e aspirações pessoais de forma a dirigir seu próprio comportamento nesta direção, considerando as exigências do meio, é de extrema importância para o sucesso dos resultados (Bandura, 1986).

No entanto, é necessário saber como interagem variáveis cognitivas, metacognitivas, emotivas, afetivas e volitivas de modo a permitir ao indivíduo agir de forma deliberada e autonomamente em interação com o meio (Simão \& Frison, 2013, p. 6).

Alguns autores pioneiros no estudo da aprendizagem autorregulada, como Schunk e Zimmerman (1998), definem-na como o processo pelo qual os estudantes, numa busca intencional pelo conhecimento, ativam e mantêm cognições, comportamentos e afetos os quais são sistematicamente orientados para atingir uma meta. Perrenoud (1999) afirma ainda que a autorregulação está relacionada com a capacidade do sujeito em gerir seus projetos, seus progressos, suas estratégias diante das tarefas e das dificuldades que surgirem. Na realidade, todas as pessoas possuem certo grau de autorregulação, mas importa que esse grau, e em especial nos e para os processos de aprendizagem formal, seja elevado, o que certamente favoreceria uma autonomia progressiva no aprender e, por extensão, na própria vida. Portanto, a autorregulação é a capacidade do ser humano de conseguir direcionar seus pensamentos, sentimentos e ações planejadas para a aquisição de metas e objetivos pessoais. Além disso, o indivíduo deve ser capaz de adaptar-se ciclicamente ao processo quando deparado por mudanças que por ventura surgirem em seu percurso (Zimmerman, 2000).

De forma sucinta, o processo de autorregulação da aprendizagem começa com a apreciação da tarefa, o que envolve os processos motivacionais, afetivos, sociais, para a definição das metas e dos objetivos que o indivíduo pretende alcançar. Continua com a elaboração de um planejamento com a ação focada na tarefa, recolhendo e selecionando a informação, materiais e outros recursos, estratégias e procedimentos que serão necessários para a execução do plano. Segue-se a execução das ações planejadas, o ajuste do planejamento anterior ao nível de exigência da tarefa atual utilizando procedimentos de autorregistro e autoinstrução, incidindo para um controle volitivo, ou seja, controle da atenção e da impulsividade, de tempo e esforço; 
finalmente, avalia os resultados, comparando-os com os pretendidos, em que sentimentos de frustração ou de sucesso poderão interferir no caminho traçado (Simão \& Frison, 2013).

\section{Metodologia}

Neste estudo, foi utilizada uma metodologia semelhante à utilizada por García, Pessoa e Sánchez (2013) para uma revisão sistemática da literatura produzida na área, que se fundamenta em uma pesquisa exploratória que "busca levantar informações sobre um determinado objeto, delimitando assim um campo de trabalho, mapeando as condições de manifestação desse objeto" (Severino, 2007, p. 123).

No intuito de obter dados concretos sobre a ocorrência da autorregulação da aprendizagem no ensino a distância em trabalhos científicos, foi realizada uma busca com o objetivo de identificar, localizar, avaliar de forma crítica e sintetizar estudos que versaram sobre a autorregulação da aprendizagem no âmbito da Educação a Distância no período de 2010 a 2015 publicados nos repositórios da Capes, no Brasil, e no RCAAP em Portugal.

\subsection{Pesquisa}

Os procedimentos desenvolvidos durante a pesquisa compreenderam o período de 2010 a maio de 2015. A busca foi realizada por meio das palavras-chave "autorregulação da aprendizagem" ou "auto-regulação da aprendizagem" e/ou "educação a distância" ou "e-learning" ou "on-line" ou "ensino a distância" ou "aprendizagem a distância". Esses descritores foram combinados e/ou substituídos pelas palavras sinônimas escritas sem aspas. Os trabalhos deveriam conter essas palavras em seu título ou em seu resumo e deveriam ser artigos, dissertações de mestrado ou teses de doutorado que deveriam ter sido publicados ou concluídos no período descrito. A pesquisa foi realizada pelas ocorrências de trabalhos no Repositório Científico de Acesso Aberto de Portugal (RCAAP) e na Coordenação de Aperfeiçoamento de Pessoal de Nível Superior, Capes. O primeiro é um portal de repositórios que permite o acesso a uma pesquisa de quarenta e dois repositórios portugueses, o que envolve um grande número de revistas científicas de caráter multidisciplinar, atas de 
conferências, teses e dissertações de mestrado, além de outras fontes de informação adicionais, como livros recentemente publicados e outras. A Capes foi escolhida por contribuir para o desenvolvimento da pesquisa brasileira de forma significativa, em seu portal periodicos.capes.gov.br, da qual participam gratuitamente as instituições federais de ensino superior, instituições de pesquisa com pós-graduação avaliada pela Capes, instituições públicas de ensino superior estaduais e municipais com pósgraduação avaliada com nota 4 pela Capes e instituições privadas de ensino superior com pelo menos um doutorado com avaliação trienal 5 ou superior pela Capes.

Uma vez que o portal de periódicos da Capes conta apenas para a busca de artigos, também foi utilizado o portal <bancodeteses.capes.gov.br>, o qual conta com teses de mestrado e doutorado de todas as instituições participantes descritas acima.

\subsection{Seleção}

Apesar de inicialmente aparecerem muitos resultados para as palavras-chave mencionadas, após a leitura do resumo foi verificado que muitos estudos não estavam relacionados com o tema escolhido. Destes, poucos foram encontrados que se enquadrassem nos critérios de busca e objetivo da pesquisa. No total foram encontrados nove trabalhos, sendo um artigo, seis dissertações de mestrado e duas teses de doutorado.

Uma vez obtidos e lidos, os trabalhos foram submetidos à análise, o que permitiu validar e preencher as categorias delimitadas previamente com intenção de configurar um quadro síntese. Foram excluídos os trabalhos coincidentes em diferentes palavras-chave pesquisadas e encontram-se representados no Quadro 1, que também demonstra os resultados desses trabalhos sob as seguintes categorias: i) tipo de trabalho (artigo, tese de mestrado ou doutorado); ii) título; iii) autor; iv) ano; vi) repositório ou revista; e vii) palavras-chave. 
Quadro 1: Trabalhos selecionados para análise

\begin{tabular}{|c|c|c|c|}
\hline & Título/Autor/Ano & Repositório & $\begin{array}{l}\text { Palavras- } \\
\text { chaves }\end{array}$ \\
\hline \multirow{5}{*}{ Artigo } & \multirow{5}{*}{$\begin{array}{l}\text { Potencial educativo dos e-portfólios (Alves, } \\
\text { 2010) }\end{array}$} & \multirow{5}{*}{$\begin{array}{c}\text { RCAAP / } \\
\text { Universidade do } \\
\text { Minho / Revista e- } \\
\text { curriculum PUC-São } \\
\text { Paulo }\end{array}$} & 7 \\
\hline & & & 5 \\
\hline & & & 3 \\
\hline & & & 9 \\
\hline & & & 1 \\
\hline \multirow{24}{*}{$\begin{array}{l}\text { Dissertação } \\
\text { de mestrado }\end{array}$} & \multirow{3}{*}{$\begin{array}{c}\text { A autorregulação da aprendizagem do } \\
\text { inglês - Um estudo de caso com recurso } \\
\text { ao e-portfólio (Rodrigues, 2012) }\end{array}$} & \multirow{3}{*}{$\begin{array}{l}\text { RCAAP / } \\
\text { Universidade do } \\
\text { Minho }\end{array}$} & 8 \\
\hline & & & 4 \\
\hline & & & 2 \\
\hline & \multirow{7}{*}{$\begin{array}{c}\text { Aprendizagem em ações educacionais a } \\
\text { distância: fatores influentes no } \\
\text { desempenho acadêmico de universitários } \\
\text { (Martins, 2012) }\end{array}$} & \multirow{7}{*}{$\begin{array}{l}\text { Capes e RCAAP / } \\
\text { Universidade de São } \\
\text { Paulo }\end{array}$} & 2 (Capes) \\
\hline & & & 4 (Capes) \\
\hline & & & 8 (Capes) \\
\hline & & & 2 (Rcaap) \\
\hline & & & 9 (Racaap) \\
\hline & & & 4 (Racaap) \\
\hline & & & 6 (Racaap) \\
\hline & \multirow{5}{*}{\begin{tabular}{|} 
Metacognição e autorregulação da \\
aprendizagem em cursos a distância: \\
estratégias de estudo e percepções sobre o \\
contexto de ensino de servidores públicos \\
(Nascimento, 2011)
\end{tabular}} & \multirow{5}{*}{$\begin{array}{c}\text { Capes e RCAAP / } \\
\text { Universidade Católica } \\
\text { de Brasília }\end{array}$} & 7 (Capes) \\
\hline & & & 3 (Capes) \\
\hline & & & 1 (Capes) \\
\hline & & & 7 (Racaap) \\
\hline & & & 2 (Racaap) \\
\hline & \multirow{3}{*}{$\begin{array}{l}\text { O papel do tutor na Educação a Distância } \\
\text { em instituição pública (Kaminski, 2012) }\end{array}$} & \multirow{3}{*}{$\begin{array}{l}\text { Capes / Universidade } \\
\text { Federal do Paraná }\end{array}$} & 8 \\
\hline & & & 4 \\
\hline & & & 2 \\
\hline & \multirow{3}{*}{$\begin{array}{c}\text { Preditores de fatores relacionados a evasão } \\
\text { e a persistência discente em ações } \\
\text { educacionais a distância (Umekawa, 2014) }\end{array}$} & \multirow{3}{*}{$\begin{array}{c}\text { RCAAP / } \\
\text { Universidade de São } \\
\text { Paulo }\end{array}$} & 8 \\
\hline & & & 6 \\
\hline & & & 2 \\
\hline & \multirow{3}{*}{$\begin{array}{c}\text { Vale a pena reflectir quando se aprende } \\
\text { on-line? Autorregulação em e-English } \\
\text { (Gago, 2012) }\end{array}$} & \multirow{3}{*}{$\begin{array}{l}\text { RCAAP / } \\
\text { Universidade Nova } \\
\text { de Lisboa }\end{array}$} & 5 \\
\hline & & & 5 \\
\hline & & & 1 \\
\hline \multirow{4}{*}{$\begin{array}{l}\text { Tese de } \\
\text { doutorado }\end{array}$} & $\begin{array}{c}\text { A gestão da aprendizagem em ambiente } \\
\text { virtual (Martins, 2014) }\end{array}$ & $\begin{array}{c}\text { RCAAP / } \\
\text { Universidade do } \\
\text { Minho } \\
\end{array}$ & 8 \\
\hline & \multirow{3}{*}{\begin{tabular}{|c|} 
As aplicações hipermédia podem promover \\
o sucesso escolar e a autorregulação da \\
aprendizagem? Análise da eficácia de uma \\
aplicação hipermédia (Pinto, 2014)
\end{tabular}} & \multirow{3}{*}{$\begin{array}{l}\text { RCAAP / } \\
\text { Universidade do } \\
\text { Minho }\end{array}$} & 2 \\
\hline & & & 4 \\
\hline & & & 8 \\
\hline
\end{tabular}

Fontes: Capes (2015), RCAAP (2015). 


\section{Resultados e discussão}

Dos resultados encontrados - um artigo, seis dissertações de mestrado e duas teses de doutorado -, a Universidade do Minho é responsável pela realização de quatro trabalhos, vindo em seguida a Universidade de São Paulo, com a realização de dois trabalhos, um realizado pela Universidade Nova de Lisboa, um realizado pela Universidade Federal do Paraná e um trabalho realizado pela Universidade Católica de Brasília.

A apresentação do artigo de Alves (2010) difere dos demais, pois se trata de uma revisão bibliográfica, não contendo as mesmas características das dissertações e teses, e teve como objetivo discutir os diferentes tipos de portfólios e a forma como estes podem ser explorados em contextos educacionais por meio de revisão de literatura.

Os Quadros 2 e 3 apresentam respectivamente as dissertações de mestrado e as teses de doutorado, com informações complementares concernentes ao objetivo geral, amostra/nível de ensino e instrumentos utilizados pelos investigadores, de forma a auxiliar a análise dos resultados.

A partir da análise dos resultados dos referidos trabalhos, pode-se verificar que os estudos de Alves (2010) e Rodrigues (2012) revelam que no portfólio há um forte potencial no desenvolvimento de competências reflexivas dos alunos, pois estes precisam ter atuação ativa em sua construção, nas tarefas de planificação, execução e avaliação, tornando-o assim um poderoso instrumento de autorregulação da aprendizagem, quer seja desenvolvido por alunos, quer seja desenvolvido por professores. Rodrigues (2012) realizou sua investigação com alunos do $5^{\circ}$ ano do Ensino Básico, a fim de promover e compreender uma aprendizagem autorregulada com recurso ao e-portfólio. Concluiu que quando os portfólios são adotados em versões digitais aumentam o seu potencial reflexivo, pois, ao assumir uma dimensão multi(hiper)média e ter maior visibilidade na internet, podendo ser vistos por um número incontrolável de pessoas, os alunos assumem maior responsabilidade naquilo que estão a produzir. Para tal, são acrescidas competências tecnológicas e ainda a possibilidade de ser desenvolvido de forma mais partilhada, colaborativa e/ou coletiva.

No estudo de Martins (2012), a ocorrência da aprendizagem em ações educacionais a distância é explicada pela frequência do uso de ferramentas da web, por 
estratégias de aprendizagem autorregulatória e reações favoráveis aos procedimentos instrucionais. De forma resumida, uma das conclusões do autor é de que a utilização de estratégias autorregulatórias da aprendizagem, como a manutenção da atenção, da calma diante das dificuldades e obstáculos diversos, revisão da matéria, elaboração de perguntas de forma a checar o conhecimento adquirido, busca ativa de ajuda quando necessário, associação de conteúdos do curso com conhecimentos prévios, esforço ativo diante da percepção de desinteresse e falta de concentração etc. são variáveis preditoras de aprendizagem e contribuem para uma avaliação positiva das ações educacionais a distância. O Quadro 2 demonstra os instrumentos utilizados pela autora. Umekawa (2014) também aponta para a relevância do uso de estratégias que promovam o autogerenciamento dos processos de ensino e aprendizagem, a autorregulação da motivação/ansiedade e a busca por ajuda interpessoal. Ou seja, a autorregulação da aprendizagem entra em cena como mais um fator importante para o sucesso escolar do aluno de educação a distância, entre outros inerentes ao contexto específico desta modalidade de ensino, tais como a importância do ambiente virtual de aprendizagem e a troca de mensagens entre alunos e tutores. Além da autorregulação da aprendizagem, também é demonstrada a importância da autorregulação das emoções para que se consiga manter o foco na tarefa e suprimir o comportamento inadequado sob instrução. Ambos os estudos foram realizados com alunos do Ensino Superior.

Com relação às estratégias individuais de estudo deliberado utilizadas por alunos de educação a distância, no que tange à metacognição, Nascimento (2011) afirmou que os tutores do curso de formação investigado incitam seus alunos a refletir sobre o modo como aprendem. Os alunos do referido estudo, servidores públicos, sentem-se motivados a estudar mais pelos tutores e pela percepção positiva acerca da atitude dos mesmos. Kaminski (2012) realizou sua investigação com 12 tutoras de um curso online no ensino superior, buscando caracterizar o papel do tutor no ensino a distância. Concluiu que o tutor é um mediador cognitivo e afetivo do conhecimento que tem a sua atividade pautada pela ampliação do poder de autorregulação do aluno no que se refere à compreensão de sua realidade a partir do conhecimento elaborado e da gestão de sua afetividade. Ou seja, quando o tutor incentiva seus alunos a refletir sobre o modo como aprendem, a utilizar de forma intencional estratégias de aprendizagem, contribuem significativamente para o aumento dos processos de autorregulação da aprendizagem dos mesmos. 
Em Gago (2012), os resultados obtidos apoiam a existência de uma correlação entre a autorregulação da aprendizagem e o desempenho dos alunos, sustentada pela literatura, mas não permitem apoiar a possibilidade de aumentar a capacidade autorregulatória dos alunos por meio do desenho instrucional. Após a frequência da unidade de aprendizagem na disciplina de Língua Inglesa com alunos do 70 ano do Ensino Básico de uma escola pública, os resultados obtidos pela aplicação dos questionários descritos no Quadro 2 revelaram que houve decréscimo do uso de estratégias de autorregulação da aprendizagem, bem como uma descrença por parte dos aprendentes na sua utilidade, mesmo com aumento do desempenho. A autora considerou que os resultados constituíram uma ameaça à validade do estudo, pois não são coerentes com os pressupostos do modelo cíclico de aprendizagem, no qual a experiência do aprendente é determinante para a sua crença positiva para aprender, ou seja, sua autoeficácia (Bandura, 1989; Silva, Simão \& Sá, 2004; Zimmerman, 2000). Entretanto, a utilização dos recursos tecnológicos ou de um determinado desenho instrucional não garante por si só aumento dos processos de autorregulação da aprendizagem. Os alunos necessitam de espaço e tempo ao nível da prática curricular em tarefas que possibilitem a reflexão, a estruturação e a construção sobre sua própria aprendizagem (Lima \& Silva, 2010).

Pinto (2014) buscou avaliar a eficácia da ferramenta hipermídia para melhorar as competências de autorregulação dos alunos do $8^{\circ}$ ano do Ensino Básico e seu rendimento em Matemática. Verificou que trabalhar os conteúdos de Matemática no tópico Teorema de Pitágoras utilizando a ferramenta Aplicação Hipermídia do Teorema de Pitágoras (AHTP) é mais eficaz do que trabalhar os mesmos conteúdos sem recurso à aplicação, pois melhoraram as competências de autorregulação da aprendizagem e o rendimento escolar dos referidos alunos. O autor realça que a ferramenta AHTP foi elaborada considerando os pressupostos referidos na literatura que potenciam a melhoria da aprendizagem dos alunos quando utilizam ferramenta hipermídia. Dessa forma, busca proporcionar uma aprendizagem interativa que favoreça os processos autorregulatórios no que diz respeito à planificação (ativando o conhecimento prévio) e à execução (monitorando as várias etapas para um resultado), com apoio sistemático do professor/tutor dando um feedback apropriado. A estrutura flexível da ferramenta hipermídia possibilita ao aluno mover-se dentro dela de acordo com a eficiência e a rapidez com que realiza as tarefas etc. (Azevedo, Johnson, Chauncey \& Graesser, 2011). A AHTP faz parte de um projeto de investigação, o Hypatiamat (disponível em 
http://www.hypatiamat.com) que pretende mapear as condições de (in)sucesso na disciplina de Matemática e contribuir para a promoção do sucesso escolar dos alunos do Ensino Básico em Portugal (Pinto, 2014).

Martins (2014) objetivou investigar a apropriação da autonomia pelos alunos de um curso de especialização. Seus resultados indicaram um perfil autoritário dos professores e mensagens que pressupõem a dependência dos aprendentes. Foi observada a autonomia manifesta em quatro níveis: dependência, proatividade, aprendência metacognitiva (senso crítico para reconhecer os limites do seu conhecimento) e capacidade de intervenção, que não são estáticos ou exclusivos. Como a autonomia está diretamente relacionada às ações intencionais de planejamento, execução e avaliação necessárias à autorregulação da aprendizagem, esse trabalho foi incluído no estudo por ter sido considerado relevante. Quando a autonomia é cerceada, pressupõe-se que prejudica os processos autorregulatórios, pois os alunos não são estimulados a buscar a aprendizagem por si mesmos e esperam receber conteúdos de forma passiva. Nesse caso, um perfil autoritário dos professores se contrapõe à promoção da autonomia dos estudantes para participação democrática na aprendizagem apoiada pela tecnologia, tal como pode ocorrer com a utilização da plataforma Moodle (Soeiro, Figueiredo \& Ferreira, 2012; 2015).

A análise dos resultados das referidas investigações centrou-se nos aspectos relacionados mais diretamente à autorregulação da aprendizagem de forma a atingir o objetivo deste estudo. As investigações sobre esse tema incidem para quatro abordagens principais; o portfólio, como instrumento com imenso potencial para a aprendizagem autorregulada; as estratégias de aprendizagem, como extremamente importantes nos processos de autorregulação; estudos centrados no tutor e na forma como estes podem promover a autorregulação nos alunos; e, por último, as TIC, ou seja, aplicações hipermédia como apoio à aprendizagem autorregulada. 


\section{Quadro 2: Informações complementares das dissertações selecionadas}

\begin{tabular}{|c|c|c|c|}
\hline $\begin{array}{l}\text { Autores, } \\
\text { ano }\end{array}$ & Objetivo & $\begin{array}{l}\text { Amostra / } \\
\text { Nível de } \\
\text { ensino }\end{array}$ & $\begin{array}{c}\text { Instrumentos utilizados na recolha dos } \\
\text { dados }\end{array}$ \\
\hline $\begin{array}{l}\text { Rodrigues, } \\
\text { M. C., } 2012\end{array}$ & $\begin{array}{l}\text { Promover e compreender uma } \\
\text { aprendizagem autorregulada com } \\
\text { recurso ao e-portfólio. }\end{array}$ & $\begin{array}{l}23 \text { alunos do } \\
50 \text { ano do } \\
\text { Ensino Básico }\end{array}$ & $\begin{array}{l}\text { Questionário: "A Aprendizagem do Inglês/O } \\
\text { Computador/O Portfólio"; Fichas de } \\
\text { autorregulação e autoavaliação; } \\
\text { Autoavaliação do e-portfólio; Autoavaliação } \\
\text { final; Ficha de reflexão sobre a construção do } \\
\text { e-portfólio. }\end{array}$ \\
\hline $\begin{array}{l}\text { Martins, L. } \\
\text { B., } 2012\end{array}$ & $\begin{array}{l}\text { Propor e testar um modelo de } \\
\text { avaliação de ações educacionais } \\
\text { ofertadas a distância, visando } \\
\text { identificar variáveis preditoras de } \\
\text { aprendizagem relacionadas às } \\
\text { características da clientela (estratégias } \\
\text { de aprendizagem e frequência nos } \\
\text { recursos da web) e às reações aos } \\
\text { procedimentos instrucionais e ao tutor. }\end{array}$ & $\begin{array}{l}343 \text { alunos do } \\
\text { Ensino Superior }\end{array}$ & $\begin{array}{c}\text { Questionários de estratégias de } \\
\text { aprendizagem, reação aos procedimentos } \\
\text { instrucionais e reação ao desempenho do } \\
\text { tutor, os quais, anteriormente à coleta de } \\
\text { dados, sofreram modificações para se } \\
\text { adequar às especificidades dos contextos de } \\
\text { Ensino Superior (validação semântica e ou } \\
\text { por juízes). }\end{array}$ \\
\hline $\begin{array}{c}\text { Nascimento, } \\
\text { T. P. C., } \\
2011\end{array}$ & $\begin{array}{l}\text { Investigar as estratégias individuais de } \\
\text { estudo deliberado utilizadas por } \\
\text { servidores públicos participantes de } \\
\text { cursos on-line, considerados os } \\
\text { aspectos da metacognição e da } \\
\text { autorregulação da aprendizagem. }\end{array}$ & $\begin{array}{l}214 \text { estudantes } \\
\text { de cursos de } \\
\text { formação de } \\
40 \text { h realizado } \\
\text { por servidores } \\
\text { públicos }\end{array}$ & $\begin{array}{l}\text { Questionário sobre estratégias de estudo } \\
\text { deliberado e percepções sobre o ensino em } \\
\text { contexto de cursos a distância on-line. }\end{array}$ \\
\hline $\begin{array}{l}\text { Kaminski, } \\
\text { C., } 2012\end{array}$ & $\begin{array}{l}\text { Caracterizar o papel do tutor na } \\
\text { educação a distância em instituição } \\
\text { pública, buscando contribuir para o } \\
\text { redimensionamento desse papel. }\end{array}$ & $\begin{array}{l}12 \text { tutoras do } \\
\text { curso de } \\
\text { Pedagogia a } \\
\text { distância de } \\
\text { instituição } \\
\text { pública }\end{array}$ & $\begin{array}{c}\text { Entrevistas, observações e levantamento } \\
\text { bibliográfico especializado. }\end{array}$ \\
\hline $\begin{array}{l}\text { Umekawa, } \\
\text { E. E. R., } \\
2014\end{array}$ & $\begin{array}{c}\text { Propor e testar um modelo de } \\
\text { avaliação de ações educacionais } \\
\text { ofertadas a distância, buscando } \\
\text { identificar variáveis preditoras de } \\
\text { elementos ligados à evasão e à } \\
\text { persistência acadêmica (contexto de } \\
\text { estudo, desenho do treinamento e o } \\
\text { próprio estudante) relacionadas às } \\
\text { características da clientela (dados } \\
\text { sociodemográficos e estratégias de } \\
\text { aprendizagem). }\end{array}$ & $\begin{array}{l}126 \text { alunos do } \\
\text { Ensino Superior }\end{array}$ & $\begin{array}{c}\text { Questionários de estratégias de } \\
\text { aprendizagem e escala de fatores } \\
\text { relacionados à evasão e a persistência em } \\
\text { EaD, sendo que os mesmos sofreram } \\
\text { alterações a fim de se ajustar às } \\
\text { particularidades do contexto do Ensino } \\
\text { Superior (validação semântica e/ou por } \\
\text { juízes). }\end{array}$ \\
\hline $\begin{array}{l}\text { Gago, S. M. } \\
\text { F. } 2012\end{array}$ & $\begin{array}{c}\text { Demonstrar que é possível transpor as } \\
\text { barreiras associadas ao e-learning, } \\
\text { tornando a componente eletrônica um } \\
\text { elemento secundário que não desvirtue } \\
\text { o fator que realmente importa, a } \\
\text { aprendizagem. }\end{array}$ & $\begin{array}{l}41 \text { alunos do } \\
70 \text { ano, do } \\
\text { Ensino Básico } \\
\text { de uma escola } \\
\text { pública }\end{array}$ & $\begin{array}{c}\text { Três questionários aplicados antes e após a } \\
\text { frequência da unidade de aprendizagem. } 1 \text { - } \\
\text { Inventário de processos de autorregulação } \\
\text { da aprendizagem; } 2 \text { - Questionário da } \\
\text { percepção de instrumentalidade de } \\
\text { autorregulação da aprendizagem; e } 3 \text { - } \\
\text { Questionário da percepção de autoeficácia } \\
\text { para autorregular. }\end{array}$ \\
\hline
\end{tabular}

Fonte: Capes (2015), RCAAP (2015). 
Quadro 3: Informações complementares das teses selecionadas

\begin{tabular}{|c|c|c|c|}
\hline $\begin{array}{l}\text { Autores, } \\
\text { ano }\end{array}$ & Objetivo & $\begin{array}{l}\text { Amostra/Contexto (nível de } \\
\text { ensino no qual se realizou o } \\
\text { estudo }\end{array}$ & $\begin{array}{l}\text { Instrumentos utilizados na } \\
\text { recolha dos dados }\end{array}$ \\
\hline $\begin{array}{l}\text { Martins, J. } \\
\text { L., } 2014\end{array}$ & $\begin{array}{l}\text { Analisar a apropriação da } \\
\text { autonomia pelos aprendentes, } \\
\text { entendida como instância da } \\
\text { autoria no processo da } \\
\text { aprendizagem em curso } \\
\text { realizado em ambiente virtual. }\end{array}$ & $\begin{array}{l}400 \text { professores de escolas públicas } \\
\text { que frequentam um curso de } \\
\text { especialização em uma instituição } \\
\text { pública }\end{array}$ & $\begin{array}{c}\text { Análise de conteúdo dos registros } \\
\text { efetuados em fóruns e memoriais } \\
\text { na plataforma do curso. }\end{array}$ \\
\hline $\begin{array}{l}\text { Pinto, R. M. } \\
\text { N., } 2014\end{array}$ & $\begin{array}{c}\text { Avaliar a eficácia da } \\
\text { ferramenta hipermédia para } \\
\text { melhorar as competências de } \\
\text { autorregulação dos alunos e o } \\
\text { seu rendimento em } \\
\text { Matemática }\end{array}$ & $\begin{array}{l}62 \text { professores, } 120 \text { turmas e } \\
2.862 \text { alunos do } 8^{\circ} \text { ano de } \\
\text { escolaridade }\end{array}$ & $\begin{array}{c}\text { Testes de conhecimento da } \\
\text { Matemática no tópico Teorema de } \\
\text { Pitágoras, um questionário que } \\
\text { avalia os processos de } \\
\text { autorregulação da aprendizagem e } \\
\text { um questionário de autoeficácia } \\
\text { em Matemática. }\end{array}$ \\
\hline
\end{tabular}

Fonte: Capes (2015), RCAAP (2015).

\section{Considerações finais}

De acordo com a análise dos resultados obtidos nos estudos selecionados, verifica-se a importância da compreensão dos processos autorregulatórios da aprendizagem pelos agentes envolvidos na Educação a Distância, tanto pelos próprios alunos como por aqueles que têm a responsabilidade de promover a autorregulação, como tutores e/ou professores, gestores etc.

Verificou-se maior tendência de as investigações incidirem sobre quatro abordagens principais: i) o portfólio como instrumento com imenso potencial para a aprendizagem autorregulada, uma vez que exige atuação ativa em sua construção através das tarefas de planificação, execução e avaliação contínuas; ii) as estratégias de aprendizagem como um dos aspectos promotores da autorregulação, tais como manutenção da atenção, da calma diante das dificuldades e obstáculos diversos, revisão da matéria, elaboração de perguntas de forma a checar o conhecimento adquirido, busca ativa de ajuda quando necessário, associação de conteúdos do curso com conhecimentos prévios etc.; iii) estudos centrados no tutor e na forma como estes podem promover a autorregulação nos alunos, tal como encontrado na literatura (Azevedo et al., 2011), alunos que são acompanhados por um professor/tutor que fornece feedbacks adequados podem utilizar mais facilmente os processos de autorregulação da aprendizagem; e, por último, iv) as TIC, através de aplicações hipermídia e na forma como estas podem auxiliar a aprendizagem autorregulada, 
proporcionando aprendizagem interativa, ativando conhecimentos prévios, monitorando as diversas etapas durante o processo de aprendizagem, dando feedback apropriado etc.

Os resultados apontam para uma necessidade crescente de outras investigações na área a fim de consolidar os resultados alcançados, dirimir possíveis contradições e investigar outras abordagens para uma maior compreensão desse fenômeno. A seleção das produções científicas utilizando apenas duas bases de dados, mesmo que amplamente constituidoras dos repositórios das principais universidades do Brasil e de Portugal, pode ser uma ameaça à validade dos resultados. Portanto, estudos semelhantes podem ser desenvolvidos ampliando as bases de dados, bem como a ampliação da pesquisa em outros países.

\section{Referências}

Alves, A. P. (2010). Potencial Educativo dos e-portefólios. Revista E-Curriculum, 5(2), $1-12$.

Azevedo, R., Johnson, A., Chauncey, A., \& Graesser, A. (2011). Use of hypermedia to assess and convey sel-regulated learning. In B. Zimmerman \& D. H. Schunk (Eds.), Handbook of Self-Regulation of Learning and Performance (pp. 102-121). New York: Taylor \& Francis.

Bates, T. (2015). Teaching in a Digital Age: Guidelines for Designing Teaching and Learning for a Digital Age. (T. Bates, Ed.). E-book.

Carneiro, R., Lefrere, P., Steffens, K., \& Underwood, J. (2011). Self-Regulated Learning in Technology Enhanced Learning Environments: An European Perspective. (R. Carneiro, P. Lefrere, K. Steffens, \& J. Underwood, Eds.) (1st ed.). Rotterdam: Sense Publishers. http://doi.org/10.1007/978-94-6091-654-0

Carrasco, J. G., López, B. G., Manzano, A. G., \& Peris, F. S. (2012). Nuevos Modos de Aprendizaje en el contexto de la Sociedad del Conocimiento. In L. G. Arettio (Ed.), Sociedad del Conocimiento y Educación. (1st ed., pp. 305-340). Madrid: UNED Universidad Nacional de Educacíon a Distancia.

Delors, J., Al-Mufti, I., Amagi, I., Carneiro, R., Chung, F., Geremek, B., ... Nanzhao, Z. (1998). Educação: um tesouro a descobrir. Relatório para a UNESCO da Comissão Internacional sobre Educação para o Séc. XXI. Unesco. São Paulo.

Gago, S. M. F. (2012). Vale a pena reflectir quando se aprende on-line? Dissertação de Mestrado. Universidade Nova de Lisboa.

Garbelini, V. M. P., \& Gonçalves, E. (2015). Educação a Distâncias: Características E Direcionamentos Pedagógicos Na Era Digital. EAD Em FOCO, 5(2), 84-101. http://doi.org/10.18264/eadf.v5i2.265

García, J., Pessoa, T., \& Sánchez, J. N. G. (2013). Estudos sobre a utilização da web 
2.0 na educação em Portugal (2008-2012). Educação, Formação \& Tecnologias, $6(1), 52-67$.

Kaminski, C. (2012). O Papel Do Tutor Na Educação a Distância Em Instituição Pública. Dissertação de Mestrado. Universidade Federal do Panamá.

Litto, F. M. (1999). O Ensino a Distância no Mundo. $1^{\circ}$ Seminário de Ensino a Distância da PUC de Campinas-SP. In Associação Brasileira de Educação a Distância ABED, São Paulo: Universidade Católica de Campinas.

Martins, J. L. (2014). A gestão da aprendizagem em ambiente virtual. Tese de Doutorado. Universidade do Minho.

Martins, L. B. (2012). Aprendizagem em ações educacionais a distância: fatores influentes no desempenho acadêmico de universitários. Dissertação de Mestrado. Universidade de São Paulo.

Nascimento, T. P. C. (2011). Metacognicão e auto-regulação da aprendizagem em cursos a distância: estratégias de estudo e percepções sobre o contexto de ensino de servidores públicos. Dissertação de Mestrado. Universidade Católica de Brasília.

Pinto, R. M. N. (2014). As aplicações hipermédia podem promover o o sucesso escolar e a autorregulação da aprendizagem? Análise da eficácia de uma aplicação hipermédia. Tese de Doutorado. Universidade do Minho.

Rodrigues, M. da C. (2012). A autorregulação da aprendizagem do Inglês: Um estudo de caso com recurso ao e-portefólio. Dissertação de Mestrado. Universidade do Minho.

Schunk, D. H., \& Zimmerman, B. J. (1998). Self-regulated Learning: From Teaching to Self-reflective Practice. (D. H. Schunk \& B. J. Zimmerman, Eds.). West Lafayette: Guilford Press.

Severino, A. J. (2007). Metodologia do trabalho científico. (Cortez, Ed.) (23rd ed.). São Paulo: Cortez.

Simão, A. V., \& Frison, L. M. B. (2013). Autorregulação da Aprendizagem: Abordagens Teóricas e Desafios para as Práticas em Contextos Educativos. Cadernos de Educação | FaE/PPGE/UFPel, 45(Julho/Agosto), 2-20.

Soeiro, D., Figueiredo, A. D., \& Ferreira, J. A. G. (2012). Mediating diversity and affection in blended learning: A story with a happy ending. Electronic Journal of ELearning, 10(3), 339-348.

Soeiro, D., Figueiredo, A. D., \& Ferreira, J. A. G. (2015). Pedagogia da Autonomia e Gestão Pedagógica no Ensino Superior. In F. Gonçalves, S., Almeida, H., Neves (Ed.), Pedagogia no Ensino Supeior (1st ed., pp. 95-123). Coimbra: CINEP/IPC.

Umekawa, E. E. R. (2014). Preditores de fatores relacionados à evasão e à persistência discente em ações educacionais a distância. Dissertação de Mestrado. Universidade de São Paulo.

Zimmerman, B. J. (2000). Attaining Self-Regulation: a social cognitive perspective. In M. Boekaerts, P. R. Pintrich, \& M. Zeidner (Eds.), Handbook of self-regulation (pp. 451-502). San Diego: Academic Press. 